\title{
Endoscopic vacuum therapy with open-pore film drainage for colonic anastomotic leakage in a morbidly obese patient
}

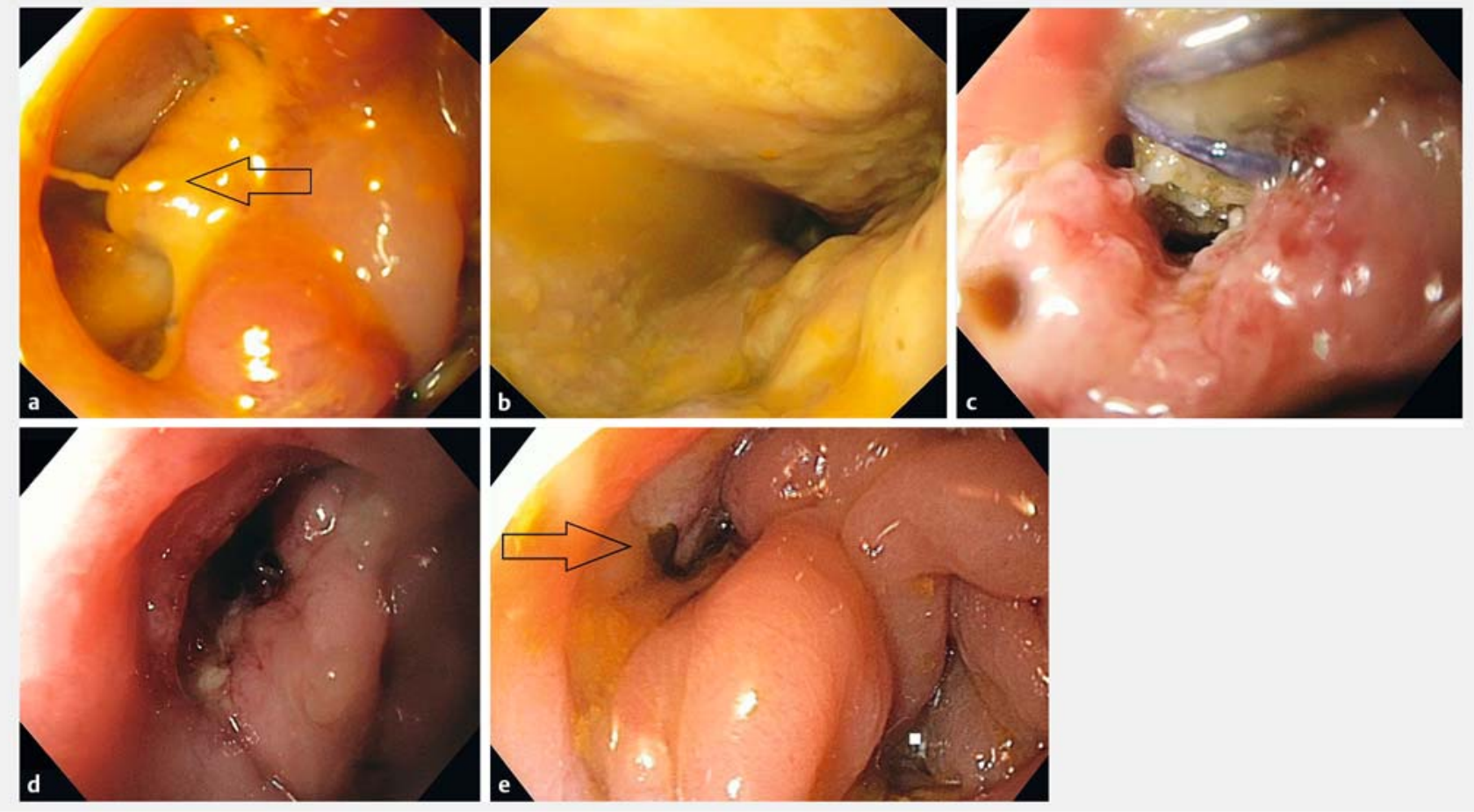

- Fig. 1 Endoscopic views of: a the site of the colonic anastomotic leakage (arrow); $\mathbf{b}$ the infected abdominal cavity seen through the anastomotic defect; $\mathbf{c}$ the suction catheter enfolded by open-pore drainage film lying at the site of the anastomotic leakage; $\mathbf{d}$ the closed anastomotic defect at the end of 9 days of EndoVAC therapy, with a residual $4-\mathrm{cm} \times 5-\mathrm{mm}$ space where the covered suction catheter was placed; e spatial niche (arrow) at the site of the now completely closed anastomotic defect 4 days after finishing the EndoVAC therapy.

Endoscopic vacuum therapy (EndoVAC) is a well-established treatment for anastomotic leakage after rectal surgery and there are a variety of other possible applications [1,2]. In the literature, there is only one case of EndoVAC being used after colon surgery, which was for treatment of an abscess [3]. We describe the first case of EndoVAC usage for a typical anastomotic leak after colon surgery that was located $30 \mathrm{~cm}$ from the anus and with direct connection to the abdominal cavity.

A 79-year-old morbidly obese man with a carcinoma of the descending colon underwent surgery with resection of the descending colon, without a stoma being created. He also suffered from many other diseases, including diabetes mellitus and coronary heart disease. He devel-

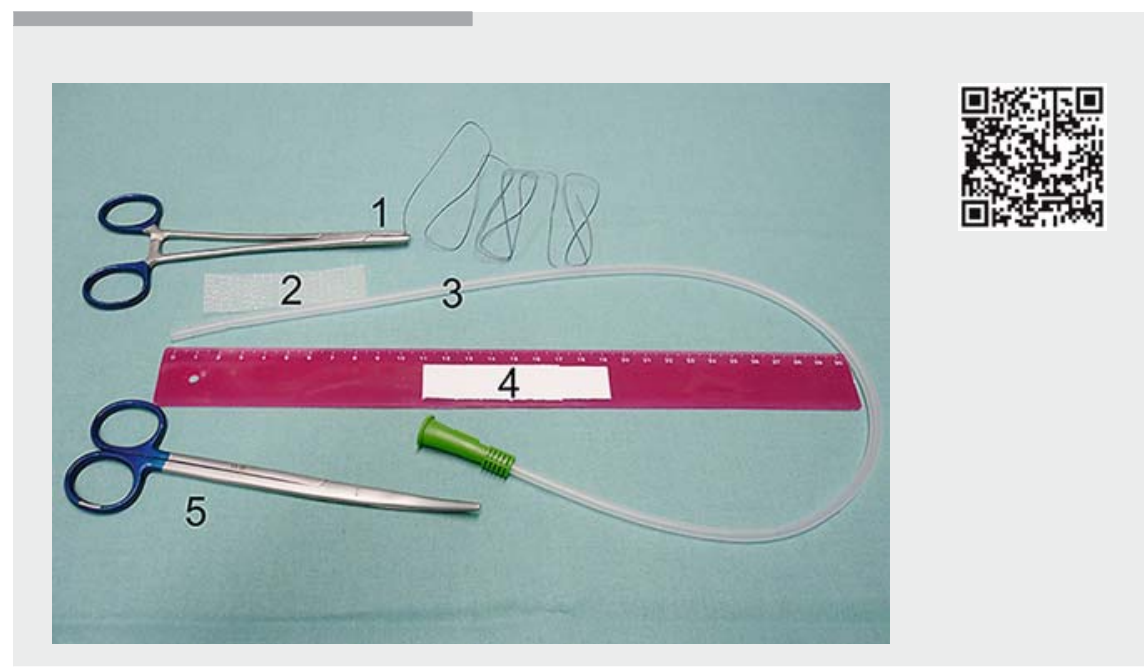

$\checkmark$ Video 1 Video demonstration of the EndoVAC technique, including the materials, endoscopic views of the anastomotic leakage, and the follow-up findings. 
oped anastomotic leakage and peritonitis 5 days after the initial surgery, which led to him undergoing relaparotomy with revision of the anastomosis. Despite this further surgery, 6 days later we again diagnosed an insufficiency and started EndoVAC therapy using a catheter covered by an open-pore drainage film instead of a sponge, which was placed into the abdominal cavity, with a continuous negative pressure of $125 \mathrm{mmHg}$ ( Fig.1a-c; $>$ Video 1).

Without a stoma, using a sponge with endoluminal EndoVAC in the colon usually leads to its dislocation owing to colonic motility, gas, and feces. With our intracavitary application, the suction kept the vacuum drainage system in place and only the 14-Fr catheter lay within the colon. We thereby avoided dislocation of the vacuum drainage system. By covering the suction catheter with an open-pore drainage film, we aimed to avoid the complications of intestinal fistula and bleeding [4,5]. The anastomotic leakage was successfully treated by 9 days of EndoVAC therapy, with the vacuum system being changed once on the third day ( $\triangleright$ Fig.1d,e). There were no complications.

Our case shows that intracavitary EndoVAC with open-pore film drainage in the abdominal cavity is a treatment option for colonic anastomotic leakage.

Endoscopy_UCTN_Code_TTT_1AQ_2AG
Competing interests

None

The authors

Ingo Wallstabe ${ }^{1}$, Phuong Nguyen ${ }^{2}$, Ingolf Schiefke ${ }^{1}$, Arved Weimann ${ }^{2}$

1 Department for Gastroenterology, Hepatology, Diabetology and Endocrinology, Klinikum St. Georg gGmbH, Leipzig, Germany

2 Department for General, Visceral and Oncological Surgery, Klinikum St. Georg gGmbH, Leipzig, Germany

\section{Corresponding author}

\section{Ingo Wallstabe, MD}

Department for Gastroenterology and Hepatology, Klinikum St. Georg gGmbH, Delitzscher Str. 141, Leipzig D-04129, Germany

Fax: +49-341-9092673

ingo.wallstabe@endoskopieren.de

\section{References}

[1] Weidenhagen R, Grützner KU, Kopp R et al. [Possibilities of vacuum therapy for the management of the septic abdomen]. Viszeralchirurgie 2006; 41: 59-68

[2] Loske G, Schorsch T, Rucktaeschel F et al. Open-pore film drainage (OFD): a new multipurpose tool for endoscopic negative pressure therapy (ENPT). Endosc Int Open 2018; 06: E865 - E871
[3] Loske G, Schorsch T, Müller C. Endoscopic intracavitary vacuum sponge therapy of anastomotic leakage in the proximal colon after right-sided colectomy. Endoscopy 2010; 42: E171 - E172

[4] Reich-Weinberger S, Schmitz M, Öfner D. New ways in the treatment of the "Open Abdomen" with a new device and the controlled negative pressure. J Wound Technol 2011; 11: $32-34$

[5] Wallstabe I, Tiedemann A, Schiefke I. Endoscopic vacuum-assisted therapy of infected pancreatic pseudocyst using a coated sponge. Endoscopy 2012; 44: E49-E50

\section{Bibliography}

DOI https://doi.org/10.1055/a-0805-0934

Published online: 14.12 .2018

Endoscopy 2019; 51: E51-E52

(c) Georg Thieme Verlag KG

Stuttgart · New York

ISSN 0013-726X

\section{ENDOSCOPY E-VIDEOS \\ https://eref.thieme.de/e-videos}

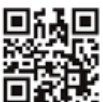

Endoscopy E-Videos is a free access online section, reporting on interesting cases and new techniques in gastroenterological endoscopy. All papers include a high quality video and all contributions are freely accessible online.

This section has its own submission website at https://mc.manuscriptcentral.com/e-videos 